\title{
Hopeful Extinctions? Tesla, Technological Solutionism and the Anthropocene
}

\author{
By Sy Taffel
}

\begin{abstract}
Over thirty years since Jean-Francois Lyotard declared the death of metanarratives, we currently find two apparently incompatible discourses that dominate imagined planetary futures. On the one hand, we encounter a metanarrative of technological progress has been fuelled by decades of advances in computational, networked, mobile and pervasive technologies. On the other, we find the apocalyptic discourse of the Anthropocene, whereby human activity is understood to be responsible for precipitating the sixth mass extinction of life in Earth's geological record. This paper explores how the divergent futures of technological solutionism and ecological catastrophism encounter one another, focusing on Tesla as a case study where technological consumerism is posited as the solution to ecological catastrophe. Critically examining the materiality of digital technoculture challenges the immaterialist rhetoric of technological solutionism that permeates both neoliberal and leftist discourses of automation, whilst questioning the 'we' that is implicit in the problematic universalisation of Anthropocenic catastrophism, instead pointing to the deeply entrenched inequalities that perpetuate networked capitalism.

Ultimately, the paper asks whether it is possible to move beyond bleak claims that we must simply "work within our disorientation and distress to negotiate life in human-damaged environments" (Tsing 2015: 131), to assemble the fragile hope that Goode and Godhe (2017) argue is necessary to move beyond capitalist realism. Hope suggests an optimism that sits uncomfortably with the reality of mass extinctions, however, the scale of the ecological crises means that we cannot afford the fatalism associated with losing hope.
\end{abstract}

Keywords: Tesla, Lithium, Cobalt, Materiality, Anthropocene, Critical Future Studies, Critical Infrastructure Studies

Taffel, Sy: "Hopeful Extinctions? Tesla, Technological Solutionism and the Anthroposcene", Culture Unbound, Volume 10, issue 2, 2018: 163-184. Published by Linköping University Electronic Press: http://www.cultureunbound.ep.liu.se 


\section{Introduction}

In contemporary society and culture - postindustrial society, postmodern culture - the grand narrative has lost its credibility.

(Lyotard 1984: 37)

Collectively imagined futures both delimit and bring forth possibilities for modes of living. The stories we tell in the present about the future fulfil a performative function that calls certain futures into view while foreclosing other possibilities, however, this performativity is modulated through a network of material constraints. This paper examines technological solutionism and the Anthropocene as two highly prominent and apparently contradictory discourses that largely dominate contemporary discussions of the future in popular culture. It brings them into conversation with one another and contemplates their relationships to Jean-Francois Lyotard's (1984) critique of metanarratives, neoliberalism, and the formulation of a fragile hope for the future that retains a critical engagement with technoculture (Goode \& Godhe 2017).

Since the 1970s computational power has grown exponentially, as have the numbers of networked computational devices, as digital technologies moved from fixed, wired spaces to wireless pervasive and mobile computing environments and the internet of things. These technocultural developments have led to a popular discourse of technological solutionism, whereby digital technology allegedly drives a cascade of disruptive and innovative changes that predominantly produce positive technological, economic, social and cultural transformations. In contradistinction to this often-uncritical enthusiasm for technological change we find the discourse of the Anthropocene, a new geological epoch in which humans - or at least assemblages in which a certain percentage of economically, socially and politically privileged humans alongside a variety of nonhuman actors - are described as transforming the conditions for life on Earth in ways that will be felt over geological temporalities (Crutzen \& Stoermer 2000, Zalasiewicz et al 2015). Arguably, if technological solutionism is the remnant of post-Enlightenment progress, the Anthropocene presents its inversion, whereby a teleological march towards utopia is supplanted by a descent into ecocide and societal collapse (Stengers 2015, Stiegler 2017).

One company which exists at the conjunction of these two discourses is Tesla Inc., the American automotive, energy storage solution and photovoltaic panel manufacturer. Tesla exemplifies how technological solutionism views Anthropocenic ecological crises as just another opportunity for venture capital-funded technology start-ups to innovate, disrupt and reshape industries in highly profitable ways. This paper presents a materialist critique of Tesla's claims surrounding ecological sustainability and market-led solutions to global ecological crises, focu- 
sing on the lithium-ion batteries employed within Tesla's electric cars and Powerwall energy storage systems.

In the concluding section I argue that whilst materialist critique can eviscerate the utopian idealism that underpins technological solutionism, this can all-too-easily fall into a cynicism where hope for the future is effectively extinguished. If academic accounts call for us to merely "work within our disorientation and distress to negotiate life in human-damaged environments" (Tsing 2015: 131), the affective impact of hope in motivating and sustaining activist endeavours to deal with ecological and social crises is negated, leading to a disempowering sense of despair. Instead, I argue that we must construct a fragile form of hope that accepts material realities surrounding the forecast for environmental conditions to become increasingly challenging as we move through the twenty-first century, but which foregrounds the potential for producing postcapitalist futures that escape the polarised and universalised metanarratives of techno-capitalism and ecological apocalypse.

\section{Metanarratives, Neoliberalism and Technological Determinism}

In The Postmodern Condition, Lyotard argues that by the end of the 1970s there had been societal and cultural shifts leading from Fordism and modernism towards a postindustrial society and a postmodern culture. Lyotard's work is commonly associated with the rejection of metanarratives; universal or grand narratives that exceed specific historical, social and political contexts to produce transcendental truths and/or teleological outcomes. Metanarratives include Enlightenment claims regarding progress (which encompassed a gradual improvement in moral, and political spheres alongside those of science and technology), the Biblical fall and redemption of (hu)man(ity), and the Marxist teleology that leads from capitalism through socialism to communism. In each case the metanarrative presents a reductive way of organising specific social, cultural and political events, which can also be read as form of ideological colonialism that projects European thought across the planet as a universal human condition; metanarratives are therefore deeply entwined with the power relations that produce methods for ordering knowledge.

Lyotard situates this rejection of metanarratives in relation to the production of techno-scientific knowledge, which he describes in the late 1970s as the "generalised computerisation of society" (Lyotard 1984: 47). This description of a technocultural logic dominated by information processing technologies was no doubt influenced by the advent of commercially successful personal computers; The Postmodern Condition was published in French in 1979, shortly after the introduction of the Apple II, Commodore PET and Tandy Corporation TRS-80 in 
1977 and ahead of the IBM PC that launched in 1981. Lyotard (1984: xxiv) suggests that the diffusion of digital computers led to rise of a calculative technocracy whereby decisions are predominantly managed:

Following a logic which implies that their elements are commensurable and that the whole is determinable. They allocate our lives for the growth of power. In matters of social justice and of scientific truth alike, the legitimation of that power is based on its optimizing the system's performance - efficiency.

This focus upon quantifiability, calculability and efficiency is unerringly close to some of the central values commonly associated with neoliberalism.

Neoliberalism is a contested term that has a wide range of sometimes contradictory deployments within academic discourse, which has seen the term dismissed as a "controversial, incoherent and crisis ridden" (Venugopal 2015: 166), and "an all-purpose denunciatory category" (Flew 2014). The term can, however, usefully demarcate "an open-ended and contradictory process of politically assisted market rule" (Peck 2010: 6), that is operative at multiple scales (including globalisation, national states, urban and local levels) (Larner 2003: 509), in which "Competition - between individuals, between firms, between territorial entities (cities, regions, nations, regional groupings) - is held to be a primary virtue," (Harvey 2005: 65). Consequently, Jodi Dean (2009: 52) defines neoliberalism as the "reformatting of social and political life in terms of its ideal of competition within markets." While such definitions do not present totalising prescriptions that elides the very real political and cultural differences between (for example) Pinochet's Chile, Thatcher's Britain, Yeltsin's Russia and Obama's America, they present a framework whereby the post-World War Two Keynesian economic doctrine was supplanted across a range of social, political and cultural contexts by the fetishisation of competition within markets.

What remains unresolved from these definitions, however, are the mechanisms that promote competition and marketisation. Here I concur with David Beer's (2016: 17) contention that technocultural apparatus of measurement play essential roles:

Systems of measurement are crucial in the realisation and deployment of what might be thought of as neoliberal political formations and the processes of neoliberalisation... Measurement is needed to enable competitors to be judged and for hierarchies of winners and losers to be created. Systems of measurement provide the mechanisms by which that competition can be enacted. Given neoliberalism's central ethos of 
competition, measurement can be seen to be a crucial part of the social fabric.

Here the synergies between Lyotard's description of computational optimisation and efficiency and the mode of governmentality associated with neoliberalism begin to become somewhat clearer, as the logic of competition requires measurement, which in turn supposes the forms of quantification and calculability that are central to technologies of information processing. Bringing increasing volumes of human experience and activity into markets; "requires technologies of information creation and capacities to accumulate, store transfer, analyse, and use massive databases to guide decisions in the global marketplace" (Harvey 2005: 3). Furthermore, these technologies of measurement, quantification and statistical prediction are not objective and neutral agents which simply record an external reality. By ascribing value to certain, quantifiable indicators, they actively shape how value is understood and so fulfil a performative function in shaping how systems develop, forming what Beer (2015) describes as productive measures. This central role of computational performativity was key to Lyotard's (1984: 46) analysis of the postmodern condition "in which the goal is no longer truth, but performativity - that is, the best possible input/output equation". Consequently, far from being tools that exist outside of globalised capitalism as was boldly proclaimed by early cyberutopians (e.g. Barlow 1996), computational systems that afford calculation, measurement and thus competition are central to the performative processes of commodification and marketisation that are emblematic of neoliberalisation.

Such an account of neoliberalism is far removed from conventional genealogies that begin with the Mont Pellerin Society and Chicago School as the genesis of the idealisation of deregulated markets and competition. Indeed, this narrative could be read as employing a fairly reductive technological determinism that conflates the numerical quantifiability of digital computers with their social and political deployments. My argument is not that digital computation inexorably leads towards a process of neoliberalisation, but that the affordances of these technologies have played and continue to perform pivotal roles in supporting, enabling and extending the domain of calculation, measurability and competition. The rhetoric of technological determinism surrounding computational technologies is not, however, primarily encountered in critiques of neoliberal governmentality, but in the techno-utopian currents associated with Silicon Valley technology start-ups, Wired magazine and the popular technology press, what has long been referred to as the "Californian Ideology" (Barbrook 1996); the idea that digital technology would make an elite extremely wealthy while making the entire world a better, more prosperous and more connected place, and it is to this prominent narrative that I turn to next. 


\section{Technological Solutionism}

The idea that technological changes precipitate social formations have a long history within media and cultural studies, dating back to Marshall McLuhan's (1964) deterministic declarations that the medium is the message and that electric media would create a global village. McLuhanite proclamations surrounding the deterministic effects of technology fell out of favour following sustained criticism in the 1970s (e.g. Enzensberger 1970, Williams 1974). However, the so-called digital revolution associated with the introduction of the personal computer in the 1980s and the World Wide Web in the 1990s saw their rehabilitation in popular culture, as exemplified by Wired magazine declaring McLuhan to be its patron saint. In this context, McLuhan's apolitical technological determinisms became a key component in the Californian Ideology.

Since the 1990s successive waves of scholarship have outlined critiques of the alleged power of networked information technologies to produce "innovative", "smart", "open", "disruptive", "revolutionary" solutions that will enrich a (predominantly male, white, North American) technologically literate elite while supposedly spreading freedom, democracy, connectivity and prosperity across the globe (e.g. Terranova 2000, Beer 2008, Fuchs 2010, McChesney 2013, Morozov 2014, Greenfield 2017). While there has been scholarship that celebrates digital utopianism, collective intelligence, and convergence culture (Negroponte 1998; Lévy 1999; Jenkins 2006; McGonigal 2011), as Jonathan Sterne (2014) highlights, critical scholarship in this area primarily addresses the highly prominent popular and corporate discourses of technological solutionism, rather than academics propagating these positions.

Two prominent examples of this discourse taken from international news stories in 2017 come from Mark Zuckerburg and Tim Cook, the respective CEOs of Facebook and Apple. Facing criticism for Facebook's role in promoting filter bubbles and fake news, Zuckerburg issued a 6,000-word post entitled Building Global Community outlining his vision for Facebook as a central pillar of community organising and a global force for good:

As we've made our great leaps from tribes to cities to nations, we have always had to build social infrastructure like communities, media and governments for us to thrive and reach the next level. At each step we learned how to come together to solve our challenges and accomplish greater things than we could alone...There are many of us who stand for bringing people together and connecting the world. I hope we have the focus to take the long view and build the new social infrastructure to create the world we want for generations to come (Zuckerberg 2017). 
Leaving aside the teleological colonial model of development, this quotation foregrounds Facebook's public facing ideology of connectivity, sharing and community (Van Dijck 2013). What is conspicuously absent from this account of what Facebook stands for is the political economy of social media, the commodification of communication and communities, predictive dataveillance, tax evasion, corporate walled gardens and rewarding venture capitalists for the free labour of billions of end users (Fuchs 2012, Scholz 2012). This does not necessarily represent the future 'we' want, and the question of who the 'we' that Zuckerberg repeatedly employs refers to is important here.

Later in 2017, Tim Cook (2017) proclaimed that "AR [Augmented Reality] is going to change everything." Expanding on what "everything" meant in this revolutionary overhaul, Cook elaborated that consumers would be able to visualise how objects would appear in their lounge before making purchases. Changing everything in the context of digital utopianism does not mean making meaningful alterations to systems of production, to eliminating (or even reducing) global, regional and local inequalities, transforming systems of governance, or addressing environmental crises; it is limited to enhancing the flexibility and ease with which affluent consumers purchase goods. The future brought into focus by these quotations is one where technology is a deterministic political actor, albeit one where the boundaries of what can or should be modified by revolutionary technologies is primarily limited to extending commodification, metrification and choice. In other words, revolutionary change within technological solutionism is delimited to the parameters of markets and competitive individualism.

Exponential change is broadly welcomed by technological solutionism. Far from there being a moment of digital revolution with periods of prior and subsequent equilibrium, there has been accelerating cascades of technocultural alterations that resonate with Stuart Hall's (2011: 723) insight that neoliberalism wants to engineer a permanent state of revolution. This increasing pace of technological flux is decried by authors for whom embodied human capacities for attention are being overloaded by the speeds associated with 24/7 digital capitalism (Berardi 2009, Crary 2013, Stiegler 2017), however, in technophilic discourse this velocity is heralded as either the paradigm of disruptive innovation, or the teleological pathway to the singularity; the moment at which exponential technological change produces an artificial superintelligence which results in unfathomable modifications to society (see Goode's article in this issue, also Kurzweil 2005; Shanahan 2015).

While the term singularity was first employed in this sense by Jon von Neumann in the 1950s (Ulam 1958: 5), the concept was popularised by technocultural narratives that drew upon the history of improvements in computational fields, projecting them into the future (Vinge 1993, Kurzweil 2005). Such accounts ac- 
cord prominence to Moore's law, the observation made by Intel co-founder Gordon Moore in 1965 that the number of transistors in a complex integrated circuit doubles annually (in 1975 Moore revised this to be bi-annually). This exponential increase has continued throughout the forty years since Moore's revised prediction, and advocates of the singularity such as Kurzweil have extended this trajectory over a 120 -year period by focusing on calculations per second per constant dollar, rather than the number of transistors, thereby allowing comparisons to be drawn between modern integrated circuits (CPUs and GPUs) and older computational technologies such as vacuum tubes and mechanical computers. Projecting this exponential increase into the future, Kurzweil (2005: 125) contends that around 2045 there will be an artificial superintelligence whose calculative power will surpass the equivalent of all human brains combined, which will profoundly alter social structures in unanticipatable ways. The discourse of the singularity predominantly advocates that this necessarily produces positive transformation of society, while pop culture critics such as Tesla CEO Elon Musk and Stephen Hawkins warn that artificial intelligence and the singularity may bring about a Terminator-esque dystopia whereby super-intelligent machines dominate humanity (Segarra 2017).

Moore's law is, however, highly unlikely to continue growing at an exponential pace for much longer. Intel's latest $8^{\text {th }}$ generation Core processors use 14 nanometre transistors, whereas the Intel Pentium processor from the mid-1990s used 800 nanometre transistors. As the size of transistors continues to shrink the material limitations of atomic sizes begins to become a potential hard limit for Moore's law. There are likely to be several further generations of microprocessor that maintain the exponential trajectory, but this is likely to cease in the 2020s, as at the 2-3 nanometre limit 'electron behaviour will be governed by quantum uncertainties that will make transistors hopelessly unreliable' (Waldrop 2016). Despite concerted research, there exists no obvious replacement for silicon integrated circuits. While digital technologies are incredibly small, fast and complex, their often-assumed immateriality is a chimera derived from a failure to grasp the speeds and scales involved in microelectronics. Although fantasies of the singularity posit computational technology as immaterial, this mistakes contingent predictions such as Moore's Law for genuine laws of physics.

While the immaterialist fantasies of the technological singularity may seem easy targets for critique, there exists homologous tendencies in sections of leftwing accelerationist literature. For example, Srnicek and Williams (2015) have influentially argued that the left must abandon the fragmented, postmodern narratives of folk-politics and a hostility towards to technology in order to construct an effective counter-hegemonic force to neoliberalism. One of the key contemporary problematics offered as being fundamentally incompatible with localised 
solutions is climate change, yet while Srnicek and Williams outline a detailed and compelling discussion of why full automation and a universal basic income would positively impact upon social inequality, there is scant discussion of how this would resolve climate change or other environmental crises. Indeed, a cursory examination of literature explicating the environmental harms caused by digital technologies (e.g. Gabrys 2011, Maxwell \& Miller 2012, Taffel 2012, Parikka 2015, Cubitt 2016) strongly suggests that vastly increasing their volume in order to automate labour would escalate environmental degradation and intensify greenhouse gas emissions rather than provide a panacea to these issues. While there are ways of conceptualising a radically repurposed circular economy that begins to address these problems, by ignoring the ecological materialities of the technologies they champion, Srnicek and Williams at times come perilously close to the discourse of technological solutionism.

\section{Anthropocenic Catastrophism}

In glaring contrast to the utopian futures of technological solutionism we find an almost completely inverted vision of the future in the shape of the ecological catastrophism associated with the contested discourse of the Anthropocene, a term demarcating the sum of recent changes to the Earth System that are global in spatial scale and will be perceptible in stratigraphic records for temporalities measured in millions of years. Whereas the discourse of technological solutionism sits uneasily around Lyotard's definition of a metanarrative - some versions epitomise the gradual, heterogenous logic of optimisation, however, the benefits of technology are problematically universalised through claims such as Here Comes Everybody (Shirky 2009), whereas the variants focusing upon the singularity clearly have a teleological and transcendental scope - the Anthropocene unmistakably presents a universal narrative which inverts the Enlightenment discourse of progress, instead positing a dystopian future of ecological collapse. Whereas technological solutionism celebrates exponential change as driving disruptive innovation, the Anthropocene predominantly views exponential change as undesirable perturbations to the ecological conditions that have fostered human civilisation. Whether discussing the unsustainable exponential increase of the human population, or the potential for positive feedbacks (such as thawing methane-laden permafrost) to drive runaway climate change, ensuring that whatever actions humans take, the planet will enter a new attractor state of hothouse Earth which cannot support more than a tiny fraction of the current human population, exponential change is characterised as destructive and unsustainable.

According to proponents of the Anthropocene: "Human activities have become so pervasive and profound that they rival the great forces of Nature and are pu- 
shing the Earth into planetary terra incognita" (Steffen, Crutzen \& McNeill 2007: 614). Planetary biodiversity is rapidly declining; the extinction rate for vertebrates is a hundred times higher than the background level and rising. This rate of extinction is only equalled within the five previous mass extinction events present in geological records, leading to claims the Anthropocene marks the sixth mass extinction of life on Earth (Ceballos et al 2015, Kolbert 2014). Over eight million tons of plastic waste enter Earth's oceans each year, and it is estimated that by 2050 there will be more plastic than fish in the oceans (World Economic Forum 2016: 7). Atmospheric concentrations of greenhouse gases such as Carbon Dioxide are at levels unseen for over 650,000 years. Extreme weather events are becoming increasingly frequent and common. Climate change refugees are becoming ever more commonplace, as rising sea levels begin rendering low-lying islands such as Tuvalu uninhabitable by humans. Human conflict, war and crises are set to be exasperated by failing harvests and multi-year droughts, with Syria providing a potential template for climate change-induced conflict (Gleick 2014). Ensuing refugee crises have provoked new nationalisms and tightened border controls. The sum of these changes appears to be that humans have been unwise enough to quarrel with the planetary ecology and are consequently discovering that organisms that damage their environment ultimately damage themselves (Bateson 1972).

There have been serious scientific proposals to commence the Anthropocene epoch at the dawn of agriculture and deforestation (Ruddiman et al 2008), colonialism and the transoceanic Columbian exchange of species (Lewis \& Maslin 2015) and the industrial revolution (as exemplified by the invention of the steam engine by James Watt in 1784) (Crutzen \& Stoermer 2000). The recommendation of the Anthropocene Working Group (AWG) to the International Geological Congress in 2016, however, strongly endorsed 1950, a date associated with the post-World War Two 'Great Acceleration' of multiple globally synchronous perturbations to the Earth System, with over $80 \%$ of the AWG indicating a preference for this date (Zalasiewicz et al. 2017: 58). While there was less agreement over the optimal primary stratigraphic marker for the Anthropocene, over 50\% of AWG members who indicated a preference opted for one of the two indicators linked to the use of nuclear weapons (Zalasiewicz et al 2017: 59). We can note the resonance between the Anthropocene as a term that gestures towards a planetary extinction event, and a stratigraphical marker which exemplifies the deliberate and systematic eradication of life.

Such a totalising and apocalyptic discourse seems to leave little scope for hope, aside from being amongst the few species to survive this mass extinction of life. The aim of those advancing the discourse within the sciences, however, is to both draw attention to the scale of this multifaceted ecological crisis and mobilise actions designed to alter the current trajectory of planetary ecological changes. 
They argue: "We are the first generation with the knowledge of how our activities influence the Earth System, and thus the first generation with the power and the responsibility to change our relationship with the planet" (Steffen et al 2011). Such calls for planetary stewardship have been criticised, however, for failing to take into account the indigenous and environmentalist movements of resistance that have struggled against colonialism, imperialism and capitalism for centuries (Bonneuil \& Fressoz 2016).

Equally, the metanarrative of the Anthropocene has come under sustained criticism for claiming that contemporary ecological crises result from the actions of a homogenised humanity, erroneously universalising actions that are primarily attributable to a small fraction of the human population (Moore 2015); for example, less than $10 \%$ of the human population are responsible for half of anthropogenic carbon dioxide emissions, while the poorest $50 \%$ are responsible for approximately $10 \%$ of emissions (Oxfam 2015). The global poor are not to blame for climate change. Consequently, an alternative hypothesis of the Capitalocene has been advanced which contends that the root cause of current ecological crises is not merely 'humans', but the capitalist mode of production that has produced a widening a metabolic rift between society and the planet (Foster, Clark \& York 2011), and which now threatens the continuation of capitalist societies (Malm 2015).

A concurrent line of critique emerges around the anthropocentricism inherent to the Anthropocene; whereas almost five hundred years of scientific discovery from Copernicus, via Darwin to the human microbiome project have gradually undermined the previously assumed centrality of humanity, the Anthropocene inverts this trend, positioning humans as a "geological superpower" (Barry \& Maslin 2016: 6). At a time where discourses of the posthuman, more-than-human and new materialism have become increasingly prominent in the humanities and social sciences, this reversion to placing an abstracted, isolated and universalised humanity at the heart of ecological change has attracted criticism for aberrantly claiming that these problems are homogenously produced by humans and failing to recognise that such activities are always the result of a polyphonic assemblage in which humans are only part of the ecological context (Haraway 2015, Tsing 2015). The Anthropocene is not solely attributable to humanity, but an assemblage that additionally contains cows, corn, combustion engines, computers, neonicotinoids, nitrogen-based fertilisers and innumerable other nonhuman agents.

If the Anthropocenic contention that humans have become a geological superpower that rivals the great forces of Nature suggests a new metanarrative of ecological catastrophe, these lines of critique - that such accounts homogenise humanity, neglect the differing roles played by diverse assemblages of nonhumans, erase centuries of struggle against colonialism and capitalism, and fail to adequately account for the inhuman role of the capitalist mode of production in 
structuring these relationships - collectively ask us to look beyond this universalism. Doing so reintroduces the possibility for hope in the Anthropocene, as moving beyond the trope of an all-encompassing ecological catastrophism re-inserts space for agencies to effect changes and implement alternative ways of living.

Whereas technological solutionism and the Anthropocene present seemingly incompatible narratives about the future, I next turn to Tesla Inc. as an enterprise which exemplifies one prominent way that technological solutionism and the Anthropocene encounter one another. As we shall see, Tesla's value is predicated upon the belief that ecological catastrophe can be averted by introducing new commodities that will effectively allow humanity to consume their way out of ecological crises. Following the neoliberal ideology that markets and competition are the optimal way of approaching complex problems, Tesla aims to save the environment by becoming the market leader in the automotive and energy storage sectors.

\section{Tesla: Technological Solutionism meets the Anthropocene}

Founded in 2003 as Tesla Motors, Tesla Inc. specialise in battery-powered electrical devices, primarily cars and Powerwall energy storage systems, with a subsidiary company (SolarCity) producing photovoltaic (solar) panels. The company's series A financing round in 2004 saw Elon Musk - who became a multimillionaire following the sale of his earlier technology start-ups Zip2 and PayPal - become chairman of the board of directors and Tesla's controlling investor. After investing \$US55 million into Tesla, who struggled to meet production schedules for their initial offering - the Roadster - Musk became Tesla's CEO in October 2008 (Baer 2014). As of October 2018, Tesla's market capitalisation is \$US50 billion, higher than that of rival automotive manufacturers such as Ford, whose market capitalisation stands at \$US34 billion. This valuation seems remarkable when considering that in 2017 Tesla sold 103,020 vehicles whereas over the same period Ford sold 6,607,000 vehicles (Ford Motor Company 2018: 2). Tesla's net income for this period was a loss of $\$$ US 2.24 billion (Tesla 2018), whereas Ford made a profit of $\$$ US 8.4 billion (Ford Motor Company 2018: 1).

Given that Tesla are making significant losses and selling 65 times less automobiles than Ford, one might legitimately question why their market valuation exceeds that of Ford. The answer is that Tesla's valuation is primarily futural in orientation, it is not predicated upon past or current performance, but represents a wager from investors who believe that Tesla will become the dominant player in the electrical vehicle and domestic energy storage sectors by importing the logic of disruptive innovation to these areas. Following in the footsteps of Steve Jobs, Bill Gates and Mark Zuckerberg, Musk is lauded as a charismatic CEO who ful- 
fils the role of the 'genius', 'visionary', individual associated with the brand. His rhetoric of mobilising "a popular uprising" (Musk quoted in Mack 2016) against the fossil fuel industries to save the planet from ecological catastrophe resonates with the permanent revolution of technological solutionism and the discourse of green capitalism. This contends that in response to Anthropocenic ecological crises, market mechanisms and individual consumption of newfound 'smart', 'green' technologies will allow the continuation of neoliberal business-as-usual. Far from being a crisis of capitalism, the Anthropocene is understood as a business opportunity. While the commodification of ecological politics is far from a novel strategy, Tesla's market valuation demarcates the extent to which investors have been willing to wager that Tesla's electric vehicles will be highly profitable solutions to climate change. Bearing this in mind, it is perhaps unsurprising that materialist critique which scrutinises Tesla's environmental and labour practices reveals that far from saving the planet, producing and powering Tesla products substantially contributes to social and environmental harms.

Generally speaking, electric vehicles (EV) produce lower greenhouse gas emissions than internal-combustion-engine vehicles (ICEV) (Miotti et al 2016), however, the respective lifecycle emissions of vehicles depend upon numerous factors, notably the longevity of the vehicle and how the electricity used to power EVs is generated. Indeed, for vehicles used for $270,000 \mathrm{~km}$ in the US midwest (or a region with a similar electricity mix) a Tesla Model S EV would have a lifecycle emission total of 61,115 kg CO2e, higher than a Mitsubishi Mirage ICEV (51,891 $\mathrm{kg}$ CO2e) (McGee 2017), correlating with other studies which have concluded that 'larger EVs can have higher lifecycle GHG emissions than smaller conventional vehicles' (Ellingsen, Singh \& Strømman 2016: 7), if electricity is primarily derived from the combustion of fossil fuels. As Tesla exclusively produce large, luxurious EVs, this suggests that far from living up the rhetoric of saving the planet, they are perpetuating the problem of greenhouse gas emissions from large personal transportation vehicles. Although EVs produce lower emissions through usage, they tend to have higher emissions associated with their production and end of life treatment (Ellingsen, Singh \& Strømman 2016: 5), entailing that they are never zero emission vehicles, and that small EVs will always produce significantly lower lifecycle emissions than Tesla's.

The extraction of materials for Tesla's lithium ion batteries is not only a significant source of greenhouse gas emissions, but has additional negative impacts on human and other biotic systems. Approximately $40 \%$ of all extracted lithium is used in manufacturing lithium-ion batteries which are also used in smartphones, laptops, tablets and other battery powered portable microelectronic devices. The battery pack in a Tesla Model S contains around $63 \mathrm{~kg}$ of lithium, as much as 10,000 mobile phones, or triple that used in some smaller EVs (Goldman Sa- 


\section{Culture Unbound}

Journal of Current Cultural Research

chs 2015: 17). Consequently, EVs are likely to treble the total global demand for lithium between 2015-2025 (Goldman Sachs 2015: 7), and already rising demand resulted in the spot market price of tripling during 2016 (Romei 2016).

Lithium is produced through evaporating water from lithium-rich brine, primarily in Andean regions of Chile, Argentina and Bolivia but also in China, or through mining lithium-rich pegmatite ores, predominantly in Australia. Over half of all the lithium produced in 2016 originated from Chile and Argentina, and along with Bolivia, these nations have around two thirds of global reserves and resources (USGS 2017). The Andean lithium triangle includes the Atacama regions of Chile and Argentina, one of the driest places on Earth which receives under four inches of rain a year. Lithium mining is a hugely water intensive process, and this has led to tensions between the multinational mining corporations and local indigenous communities who suffer shortages of drinkable water and lack functional sewerage systems. The chlorinated saltwater that is a by-product of evaporating lithium is corrosive and toxic to life, irreversibly altering Atacama's unique and fragile ecology.

According to the Washington Post, mining contracts see multinational corporations generate \$US250 million per annum in lithium sales, while indigenous groups receive annual payments of between US\$9,000-60,000 as recompense for ecological damage and water shortages (Frankel and Whoriskey 2016). As Sean Cubitt (2016: 64-70) surmises, the indigenous people of the Atacama, their culture and the unique ecology of the area become invisible under a modernised version of the colonial doctrine of terra nullius. Tesla's public image as a clean, green technology company is built upon this erasure and greenwash which erroneously contends that electric vehicles are a harmless, zero emission way of tackling climate change. The global narrative of technological solutionism here masks the material reality of the economic exploitation and ecological devastation that is all-too-commonly associated with the globalised extraction industries.

The cathode of the batteries employed by Tesla do not only contain lithium. While several distinct chemistries lithium ion batteries exist, Tesla currently utilises lithium-nickel-cobalt batteries. Cobalt has serious labour rights issues attached to its production. The Democratic Republic of Congo (DRC) produces the majority of the world's cobalt, and houses almost half of global reserves (USGS 2017: 53). DRC is one of the poorest nations on the planet, and exemplifies the 'resource curse', whereby the state's array of valuable minerals paradoxically is associated with less wealth, stability and democracy than neighbouring countries with fewer resources. Between 1996 and 2003 the two Congo wars saw around 5.4 million direct or indirect deaths (Coghlan et al 2006), and there have subsequently been enduring internal conflicts. DRC has long been associated with conflict minerals that are necessary for contemporary digital electronics, with tantalum, tin, 
tungsten and gold (all of which are mined in the North-Eastern Kivu provinces) funding warlords and militias (Taffel 2015). Cobalt has received less international attention as it is primary mined in the southern Katanga province where there has been less domestic conflict. Investigations into the conditions at Congolese cobalt mines, however, reveal workers as young as four-years-old, often earning as little as 11 US cents per hour (Crawford 2016) for manually removing ore from the ground. NGOs estimate that around 40,000 Congolese artisanal cobalt miners are children (Walther 2012). Again, we find that behind the veil of technological solutionism lurks deeply inequitable and exploitative activities.

In response to criticism surrounding the usage of Congolese cobalt, Tesla have declared an intention to source all raw materials from North America. In 2016, North American cobalt production amounted to under 8,000 tons, around 5\% of the global total (USGS 2017: 53). Tesla aim to produce 500,000 Model 3 EVs in 2018; doing so would require more cobalt than is extracted from North America (Gandon 2017), and this is before considering Tesla's other EV models and energy storage systems. Either Tesla cannot exclusively use North American cobalt, or they must produce dramatically far fewer cars than intended. The alarming gap between rhetoric and material reality is once again rendered visible through materialist critique; technological solutionism fails to acknowledge scarcities that constrain the immaterialist fantasy of abundance.

Environmentalist claims surrounding scarcity themselves should, however, be subjected to scrutiny because of a historical tendency to underestimate the potential for technological advancement. For example, Paul Ehrlich (1968: xi) predicted that "In the 1970s and 1980s hundreds of millions of people will starve to death", failing to foresee that the suite of technologies collectively known as the Green Revolution would substantially increase global food production. Similarly, theories of peak oil, beginning with M. King Huppert's (1979) 1956 predictions forecast a peak in global oil production around 2000 (Heinberg 2005), however, the development of unconventional oil sources - such as hydraulic fracturing and tar sands - have seen these predictions fail to eventuate. In both cases, however, these technological alterations are associated with significant ecological harms; the contamination of water supplies and greenhouse gas emissions associated with fracking and tar sands, and the disruptions to the nitrogen cycle associated with synthetic fertilisers and reduction in biodiversity connected to increased pesticide usage. Technological solutions may resolve particular crises, but often produce serious harms elsewhere in the Earth System. 


\section{Conclusion: Hope and Materialism}

Returning to the question of metanarratives, we should not envisage the future as being teleologically driven towards either technological salvation or ecological apocalypse, both of which negate the roles of material specificities and collective agencies in producing differences that make differences. A detailed consideration of the labour and environmental issues present in the production of Tesla's EVs punctures utopian claims that these vehicles will usher in an era of carbon neutral, environmentally friendly transportation. If we seriously consider Zuckerberg's question about building desirable futures - while removing its solutionist context - we are left questioning whether the environmental devastation, externalisation of harm onto indigenous communities, and child labour that are currently necessary for the production of Tesla's EV are desirable. If the answer is no, the question then shifts towards contemplating how to approach Anthropocenic catastrophism with hope while avoiding the immaterialist fantasy of technological solutionism.

One answer, is that in an age where anthropogenic activities are responsible for a mass extinction of life forms, there is no hope beyond Tsing's call for learning to cope with the distress and disorientation of living in degraded environments, that anything more is liable to slip into fantasies of universalist, anthropocentric discourses of control, mastery and technological solutionism. For Tsing, whereas technology can rapidly scale to form monopolistic global platforms such as Facebook, Google and Amazon, such scalability cannot extend into the realms of ecological systems. Multispecies assemblages and mutualistic transformation produce differentiated entities that can only be examined through natural history and ethnography, through local specificity rather than the expansionist command and control paradigm of mathematics and algorithms which underpins contemporary forms of computational neoliberalism.

This approach undeniably has merit, as is evidenced by the need to consider the specificities and affordances of different materials, sites and conditions of extraction associated with lithium ion batteries. However, this localism at once exemplifies the folk politics that Srnicek and Williams critique as being fundamentally incapable of addressing global social and environmental crises whilst also adopting an affective tone characterised by despair and disenchantment. This may be a realistic appraisal of the state of life in the Anthropocene, but the performative function of such writing is likely to eradicate any sense of hope. Hope is a key affect that mobilises activism and social change (Castells 2015); without hope we are likely to fall into despair and consequently succumb to the fallacy that societal collapse is the only escape from capitalist social relations. In order to challenge the exploitative system of neoliberal technocultural relations and the "deep pessimism of those who believe the future is now an inevitable catastrophe" (Goode \& Godhe 2017: 126) it is therefore crucial to find ways of mobilising a fragile form of 
hope that acknowledges the severity of contemporaneous ecological crises and the fallacies of technological solutionism, but which does not consequently reduce expectations of the future to mere survival. Instead, fragile hope must recognise the potential for significant positive change to be enacted through mobilising collective action to construct commons and publics, thereby contesting the neoliberal fetishization of markets and competition. This should not, however, be read as an opportunity to insert a metanarrative of redemption, a teleological march towards a utopian, post-antagonistic age of ecological and social harmony. Paraphrasing Gramsci, the challenge of (post)modernity is to live without illusions (of technological solutionism) without becoming disillusioned (by the scale of Anthropocenic ecological crises). It is precisely this challenge that the performative function fragile hope seeks to address.

It is pertinent here to critique precisely the kind of individualistic consumption central to Tesla's appeal, instead contemplating how technocultural systems could be redesigned to enhance socially equity and ecological resilience. Tesla produce large, luxurious, expensive EVs to function as direct replacements for the predominantly individualised mode of transportation that became dominant during the twentieth century; the solution to the problem of ICEVs is thereby understood as transforming vehicle propulsion rather than rethinking transportation systems. Rather than merely altering individual vehicles, a more environmentally sustainable, equitable and resilient transportation network could involve substantive roles for electrified public transportation alongside improved infrastructure for cyclists and pedestrians. This is not to say that EVs cannot be part of this mix, with small EVs such as the Nissan Leaf potentially offering far more promising pathways than Tesla's, however, this approach involves reconceptualising transportation as an assemblage where individual mechanised transportation plays a less dominant role. This vision for transportational infrastructure is more transformative and sustainable than one dominated by large EVs that require substantial quantities of lithium and cobalt.

For Tesla the answer to the Anthropocenic conjuncture is more individualised consumption and ever-increasing economic growth, repeating the erroneous ideology of capitalist realism which fundamentally cannot be realigned with the material reality of a finite planet. A more realistic, yet hopeful alternative involves redistributing wealth away from the $10 \%$ of the human population who are responsible for half of greenhouse gas emissions and are the privileged minority who can realistically contemplate purchasing Tesla's EVs. This does not mean rejecting technology in favour of returning to a pre-industrial state, but re-envisioning how technologies can be employed to create postcapitalist futures that escape both the naive optimism of technological solutionism and the catastrophism of the Anthropocene. While it may appear to be an oxymoron to speak of hope in an 


\section{Culture Unbound}

Journal of Current Cultural Research

age of mass extinctions, the performative function of fragile hope is a pre-requisite for escaping the despair and defeatism that makes catastrophic futures more likely to eventuate.

Sy Taffel is a senior lecturer in media studies and co-director of the Political Ecology Research Centre at Massey University, Aotearoa New Zealand. He has published work on political ecologies of digital media, media and materiality, hacktivism, and pervasive/locative media. He is a co-editor of Ecological Entanglements in the Anthropocene (Lexington, 2017 with Nicholas Holm).E-mail: $\underline{\text { S.A.Taffel@ }}$ massey.ac.nz

\section{References}

Baer, Drake (2014): "The Making Of Tesla: Invention, Betrayal and the Birth of the Roadster", https://www.businessinsider.com.au/tesla-the-origin-story-201410 ? $\mathrm{r}=\mathrm{US} \& I R=\mathrm{T}$. (accessed 24/10/2018)

Barbrook, Richard and Andy Cameron (1996): "The Californian Ideology", Science as Culture, 6:1, 44-72.

Barlow, John Perry (1996): "A Declaration of the Independence of Cyberspace", https://projects.eff.org/ barlow/Declaration-Final.html, (accessed 06/05/2014).

Barry, Andrew and Mark Maslin (2016): "The Politics of the Anthropocene: A Dialogue”, Geo: Geography and Environment, 3;2, e00022-n/a. doi: 10.1002/geo2.22.

Bateson, Gregory (1972): Steps to an Ecology of Mind: Collected Essays in Anthropology, Psychiatry, Evolution, and Epistemology, University of Chicago Press.

Beer, David (2008): "Social Network (ing) Sites... Revisiting the Story so Far: A Response to danah boyd \& Nicole Ellison", Journal of Computer-Mediated Communication, 13:2, 516-529

Beer, David (2015): "Productive Measures: Culture and Measurement in the Context of Everyday Neoliberalism", Big Data \& Society, 2:1, 1-13

Beer, David (2016): Metric Power, Basingstoke: Palgrave Macmillan.

Berardi, Franco (2009): Precarious Rhapsody, London: Minor Compositions.

Bonneuil, Christophe and Jean-Baptiste Fressoz (2016): The Shock of the Anthropocene: The Earth, History and Us, London: Verso Books.

Castells, Manuel (2015): Networks of Outrage and Hope: Social Movements in the Internet Age, John Wiley \& Sons.

Ceballos, Gerardo, Paul R. Ehrlich, Anthony D. Barnosky, Andrés García, Robert M. Pringle, and Todd M. Palmer (2015): "Accelerated Modern Human-Induced Species Losses: Entering the Sixth Mass Extinction", Science Advances, 1:5, 1-5.

Coghlan, Benjamin, Richard J Brennan, Pascal Ngoy, David Dofara, Brad Otto, Mark Clements, and Tony Stewart (2006): "Mortality in the Democratic Republic of Congo: a nationwide survey", The Lancet 367:9504, 44-51.

Crary, Jonathan (2013): 24/7: Late Capitalism and the Ends of Sleep, London and New York: Verso.

Crawford, Alex (2016): "Meet Dorsen, 8, who Mines Cobalt to make your Smartphone Work." https://news.sky.com/story/meet-dorsen-8-who-mines-cobalt-to-makeyour-smartphone-work-10784120. (accessed 24/10/2018)

Crutzen, P.J. and E.F. Stoermer (2000): "The "Anthropocene", Global Change Newsletter, 41, 17-18. International Geosphere-Biosphere Programme (IGBP).

Cubitt, Sean (2016): Finite Media: Environmental Implications of Digital Technologies, Durham: Duke University Press. 


\section{Culture Unbound}

Journal of Current Cultural Research

Dean, Jodi (2009): Democracy and Other Neoliberal Fantasies: Communicative Capitalism and Left Politics, Duke University Press.

Ellingsen, Linda Ager-Wick, Bhawna Singh and Anders Hammer Strømman (2016): "The Size and Range Effect: Lifecycle Greenhouse Gas Emissions of Electric Vehicles", Environmental Research Letters 11:5, 054010.

Enzensberger, Hans Magnus (1970): "Constituents of a Theory of the Media", New Left Review, 64, 13-36.

Fisher, Mark (2009): Capitalist Realism: Is there no Alternative?, Winchester, UK: Zero Books.

Flew, Terry (2014): "Six Theories of Neoliberalism", Thesis Eleven: 122:1, 49-71. doi: $10.1177 / 0725513614535965$.

Ford Motor Company (2018): 2017 Fourth Quarter and Full Year Financial Results, https://media.ford.com/content/dam/fordmedia/North\%20America/ US/2018/01/24/4q-17-financial.pdf (accessed 24/10/2018)

Foster, John Bellamy, Brett Clark and Richard York (2011): The Ecological Rift: Capitalism's War on the Earth, New York: Monthly Review Press.

Frankel, Todd and Peter Whoriskey (2016): "Tossed Aside in the 'White Gold' Rush", Washington Post. https://www.washingtonpost.com/graphics/business/batteries/ tossed-aside-in-the-lithium-rush/. (accessed 24/10/2018)

Fuchs, Christian (2010): "Labor in Informational Capitalism and on the Internet", The Information Society 26:3, 179-196.

Fuchs, Christian (2012): "The Political Economy of Privacy on Facebook", Television \& New Media, 13:2, 139-159.

Gabrys, Jennifer (2011): Digital Rubbish: A Natural History of Electronics, Minnesota: University of Michigan Press.

Gandon, Sebastien (2017): "No Cobalt, No Tesla", https://techcrunch.com/2017/01/01/ no-cobalt-no-tesla/. (accessed 24/10/2018)

Gleick, Peter H. (2014): "Water, Drought, Climate Change, and Conflict in Syria", Weather, Climate, and Society, 6:3, 331-340. doi: 10.1175/wcas-d-13-00059.1.

Goode, Luke and Michael Godhe (2017): "Beyond Capitalist Realism - Why We Need Critical Future Studies", Culture Unbound: Journal of Current Cultural Research, 9:1, 109-129.

Greenfield, Adam (2017): Radical Technologies: The Design of Everyday Life, Verso Books.

Hall, Stuart (2011): “The Neo-Liberal Revolution”, Cultural Studies, 25:6, 705-728. doi: 10.1080/09502386.2011.619886.

Haraway, Donna (2015): “Anthropocene, Capitalocene, Plantationocene, Chthulucene: Making Kin." Environmental Humanities, 6, 159-165.

Harvey, David (2005): A Brief History of Neoliberalism, Oxford: Oxford University Press.

Heinberg, Richard (2005): The Party's Over: Oil, War and the Fate of Industrial Societies, Forest Row: Clairview books.

Higgins, Tim (2017): "Tesla Narrowly Misses 80,000-Vehicle Sales Goal in 2016", https://www.wsj.com/articles/tesla-misses-its-2016-sales-goal-despite-27-fourthquarter-rise-1483479562. (accessed 24/10/2018)

Hubbert, M. King (1979): "Hubbert Estimates from 1956 to 1974 of US Oil and Gas", Michel Grenon (ed.): Methods and Models for Assessing Energy Resources, Oxford, UK: Pergamon Press, 370-383.

Jenkins, Henry (2006): Convergence Culture: Where Old and New Media Collide, New York: New York University Press.

Kolbert, Elizabeth (2014): The Sixth Extinction: An Unnatural History, New York: Henry Holt and Co.

Kurzweil, Ray (2005): The Singularity is Near, London: Viking Penguin.

Larner, Wendy (2003): “Neoliberalism?", Environment and Planning D: Society and 


\section{Culture Unbound}

Journal of Current Cultural Research

Space, 21, 509-512.

Lévy, Pierre (1999): Collective Intelligence: Mankind's Emerging World in Cyberspace, Cambridge, MA: Perseus Publishing.

Lewis, Simon L and Mark A Maslin (2015): "Defining the Anthropocene", Nature, 519:7542, 171-180.

Lyotard, Jean-François (1984): The Postmodern Condition: A Report on Knowledge, Minneapolis: University of Minnesota Press.

Mack, Eric (2016): “How Tesla And Elon Musk's 'Gigafactories' Could Save The World." https://www.forbes.com/sites/ericmack/2016/10/30/how-tesla-andelon-musk-could-save-the-world-with-gigafactories/\#57f2d3752de8. (accessed 24/10/2018)

Malm, Andreas (2015): "The Anthropocene Myth", https://www.jacobinmag. com/2015/03/anthropocene-capitalism-climate-change/ (accessed 24/10/2018)

Maxwell, Richard and Toby Miller (2012): Greening the Media, Oxford: Oxford University Press.

McChesney, Robert W. (2013): Digital Disconnect: How Capitalism is Turning the Internet Against Democracy, New York: New Press.

McGee, Patrick (2017): "Electric cars' green image blackens beneath the bonnet", Financial Times, November 8th 2017, https://www.ft.com/content/a22ff86e-ba37$11 \mathrm{e} 7-9 \mathrm{bfb}-4 \mathrm{a} 9 \mathrm{c} 83 \mathrm{ffa} 852$ (accessed 24/10/2018)

McGonigal, Jane (2011): Reality is Broken: Why Games Make us Better and How They Can Change the World, New York: Penguin.

McLuhan, Marshall (1964): Understanding Media: The Extensions of Man, London: Routledge.

Miotti, Marco, Geoffrey J. Supran, Ella J. Kim and Jessika E. Trancik (2016): "Personal Vehicles Evaluated against Climate Change Mitigation Targets", Environmental Science \& Technology, 50:20, 10795-10804. doi: 10.1021/acs.est.6b00177.

Moore, Jason W. (2015): Capitalism in the Web of Life: Ecology and the Accumulation of Capital, New York: Verso Books.

Morozov, Evgeny (2014): To Save Everything, Click Here: The Folly of Technological Solutionism, London: Penguin.

Negroponte, Nicholas (1998): “Beyond Digital”, http://www.wired.com/wired/archive/6.12/negroponte.html, (accessed 13/08/2013).

Oxfam (2015): "Extreme Carbon Inequality: Why the Paris climate deal must put the poorest, lowest emitting and most vulnerable people first", https://www.oxfam.org/sites/www.oxfam.org/files/file attachments/mb-extreme-carbon-inequality-021215-en.pdf. (accessed 24/10/2018)

Parikka, Jussi (2015): A Geology of Media, Minneapolis: University of Minnesota Press.

Peck, Jamie (2010): Constructions of Neoliberal Reason, Oxford University Press.

Romei, Valentina (2016): "Lithium Price on the Rise", Financial Times, April 15 2016. https://www.ft.com/content/2bfba977-4715-3466-befa-f6cf60f13d14.

Ruddiman, William F, Zhengtang Guo, Xin Zhou, Hanbin Wu and Yanyan Yu (2008): "Early Rice Farming and Anomalous Methane Trends", Quaternary Science Reviews, 27:13, 1291-1295.

Sachs, Goldman (2015): "Emerging Theme Radar: What If I Told You", http://www. goldmansachs.com/our-thinking/pages/macroeconomic-insights-folder/what-if-itold-you/report.pdf. (accessed 24/10/2018)

Scholz, Trebor (2012): Digital Labor: The Internet as Playground and Factory, New York: Routledge.

Segarra, Lisa (2017): "Elon Musk: AI Poses "Vastly More Threat Than North Korea'." http://fortune.com/2017/08/12/elon-musk-ai-poses-vastly-more-risk-than-northkorea/. (accessed 24/10/2018)

Shanahan, Murray (2015): The Technological Singularity, Cambridge, MA: The MIT 


\section{Culture Unbound}

Journal of Current Cultural Research

Press.

Shirky, Clay (2009): Here Comes Everybody: How Change happens When People Come Together, London: Penguin.

Srnicek, Nick, and Alex Williams (2015): Inventing the Future: Postcapitalism and World Without Work, London: Verso.

Steffen, Will, Paul J. Crutzen and John R. McNeill (2007): "The Anthropocene: Are Humans Now Overwhelming the Great Forces of Nature?", AMBIO: A Journal of the Human Environment, 36:8, 614-621. doi: 10.1579/0044-7447(2007)36[614:TAAHNO]2.0.CO;2.

Steffen, Will, Jacques Grinevald, Paul Crutzen and John McNeill (2011): "The Anthropocene: Conceptual and Historical Perspectives", Philosophical Transactions of the Royal Society of London A: Mathematical, Physical and Engineering Sciences, 369:1938, 842-867.

Stengers, Isabellem (2015): In Catastrophic Times: Resisting the Coming Barbarism, London: Open Humanities Press.

Sterne, Jonathan (2014): “'What Do We Want?' 'Materiality!' 'When Do We Want It?' 'Now!'”, Tarleton Gillespie, Pablo J. Boczkowski and Kirsten A. Foot (eds): $M e-$ dia Technologies: Essays on Communication, Materiality and Society, Cambridge, MA: The MIT Press.

Stiegler, Bernard (2017): Automatic Society: The Future of Work, New York: John Wiley \& Sons.

Taffel, Sy (2012): "Escaping Attention: Digital Media Hardware, Materiality and Ecological Cost", Culture Machine 13, 1-28.

Taffel, Sy (2015): "Towards an Ethical Electronics? Ecologies of Congolese Conflict Minerals", Westminster Papers in Communication and Culture, 10:1, 18-33.

Terranova, Tiziana (2000): "Free Labor: Producing Culture for the Digital Economy", Social text 18:2, 33-58.

Tesla (2018): United States Securities and Exchange Commision Form 10-K Annual Report for the Fiscal Year Ending Sunday, December 31, 2017

Tsing, Anna Lowenhaupt (2015): The Mushroom at the End of the World: On the Possibility of Life in Capitalist Ruins, Princeton and Oxford: Princeton University Press.

Ulam, S. (1958): “John von Neumann 1903-1957”, Bulletin of the American Mathematical Society, 64, 1-49.

USGS (2017): Mineral Commodites Summaries 2017. US Geological Survey.

Van Dijck, Jose (2013): The Culture of Connectivity: A Critical History of Social Media, New York: Oxford University Press.

Venugopal, Rajesh (2015): "Neoliberalism as Concept", Economy and Society, 44:2, 165-187. doi: 10.1080/03085147.2015.1013356.

Vinge, Vernor (1993): "The Coming Technological Singularity", Whole Earth Review, 81, 88-95.

Waldrop, M Mitchell (2016): "The Chips are Down for Moore's Law", Nature, 530:7589, 144-147.

Walther, Cornelia (2012): "In DR Congo, UNICEF Supports Efforts to Help Child Labourers Return to School", UNICEF, https://www.unicef.org/childsurvival/drcongo 62627.html. (accessed 24/10/2018)

Williams, Raymond (1974): Television: Technology and Cultural Form, London: Routledge.

World Economic Forum (2016): The New Plastics Economy: Rethinking the Future of Plastics, http://www3.weforum.org/docs/WEF_The_New_Plastics_Economy.pdf (accessed 24/10/2018)

Zalasiewicz, Jan, Colin N Waters, Mark Williams, Anthony D Barnosky, Alejandro Cearreta, Paul Crutzen, Erle Ellis, Michael A Ellis, Ian J Fairchild, and Jacques Grinevald (2015): "When did the Anthropocene Begin? A Mid-Twentieth Century 


\section{Culture Unbound}

Journal of Current Cultural Research

Boundary Level is Stratigraphically Optimal", Quaternary International, 383, 196-203.

Zalasiewicz, Jan, Colin N Waters, Colin P Summerhayes, Alexander P Wolfe, Anthony D Barnosky, Alejandro Cearreta, Paul Crutzen, Erle Ellis, Ian J Fairchild, and Agnieszka Gałuszka (2017): "The Working Group on the Anthropocene: Summary of evidence and interim recommendations", Anthropocene, 19, 55-60.

Zuckerberg, Mark (2017): "Building Global Community", https://www.facebook. com/notes/mark-zuckerberg/building-global-community/10154544292806634/. (accessed 24/10/2018) 